\title{
Expectations and beliefs: How single young gay, bisexual and other men who have sex with men envision romantic relationships
}

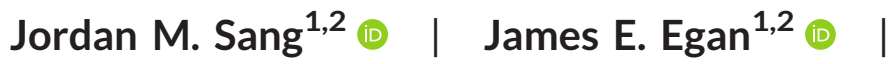

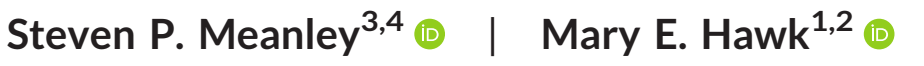 \\ Nina Markovic ${ }^{2,5}$ \\ Todd M. Bear ${ }^{1} \oplus$ | Derrick D. Matthews ${ }^{6}$ ( ) ।
}

José A. Bauermeister ${ }^{3,4}$

${ }^{1}$ Department of Behavioral and Community Health Sciences, Graduate School of Public Health, University of Pittsburgh, Pittsburgh, Pennsylvania, USA

${ }^{2}$ Center for LGBT Health Research, University of Pittsburgh, Pittsburgh,

Pennsylvania, USA

${ }^{3}$ School of Nursing, University of Pennsylvania, Pittsburgh, Pennsylvania, USA

${ }^{4}$ Program on Sexuality, Technology \& Action Research, University of Pennsylvania,

Philadelphia, Pennsylvania, USA

${ }^{5}$ School of Dental Medicine, University of Pittsburgh, Philadelphia, Pennsylvania, USA

${ }^{6}$ Department of Health Behavior, Gillings School of Public Health, University of North Carolina, Chapel Hill, North Carolina, USA

\section{Correspondence}

Jordan M. Sang, BC Centre for Excellence in HIV/AIDS, 505-1200 Burrard St, Vancouver, BC V6Z $1 Z 5$.

Email: jsang@bccfe.ca

Funding information

National Institutes of Health,

Grant/Award Number: K01-MH087242

\begin{abstract}
We developed measures of relational beliefs and expectations among single young gay and bisexual men (YGBM). Data come from an online cross-sectional study YGBM, which ran from July 2012 until January 2013. There were 50 items on relational beliefs and 25 items on relational expectations. We used random split samples and a priori analysis to group items together and applied principal axis factoring with varimax orthogonal rotation. We had a total $N=1582$ in our analytical sample and identified six constructs of relational expectations (restrictions, negative break up, masculine and gender norms, optimism, cheating, immediacy) and two constructs of relational beliefs (sex beliefs, equality). Our findings highlight specific relational cognitions among YGBM and offer insight into the beliefs and expectations that may inform their relationships. Findings may be useful for health professionals to help YGBM reflect and understand the health implications of their beliefs and expectations about same-sex relationships to promote healthy decisionmaking as they seek future partners.
\end{abstract}

KEYWORDS

cognition, dating, factor analysis, relationships, sexual minority 


\section{1 | INTRODUCTION}

Romantic relationships help fulfill the innate human desire for connection and to feel loved (Furman \& Wehner, 2003). These relationships are defined by physical and emotional intimacy, which are constructs of romantic love (Collins et al., 2009). While romantic relationships develop naturally and change through the life course, the cognitive processes of love and relationships that inform relationship schemas begin at a young age (Collibee \& Furman, 2016; Nosko et al., 2011). Adolescence is a critical time for cognitive growth and development of romantic relationships and these relationships influence healthy social and emotional development (Steinberg \& Morris, 2001). Romantic relationships may also provide emotional support and companionship and help to buffer stress (Wienke \& Hill, 2009). The latter finding is especially relevant for young gay, bisexual and other men who have sex with men (YGBM) who experience unique internal and external sexuality-related stressors compared to their heterosexual peers (Bauermeister et al., 2010; Meyer, 2003).

Relational cognitions refer to mental schemas that individuals create to model how relationships work, including the roles people should play, expectations about what will happen, and how people should behave within relationships. These mental schemas include thoughts, feelings and behaviors that affect the quality of relationships and well-being (Holt et al., 2016; Sprecher \& Metts, 1989; Stackert \& Bursik, 2003). Some authors suggest that while most individuals are unaware of their relational cognitions, by understanding their own cognitions individuals can better monitor and self-regulate their behavior and, in turn, improve mental well-being (Sullivan \& Schwebel, 1995). Health promoting cognitions are related to personal growth and adjustment in relationships, conflict resolution, communication, problem solving, and expressing love (Meier \& Allen, 2009; Sullivan \& Schwebel, 1995; Vannier \& O'Sullivan, 2018). Conversely, unrealistic expectations may be harmful to mental well-being, and are associated with lower relationship satisfaction, commitment, and investment (Soller, 2014; Vannier \& O'Sullivan, 2018).

Within the human immunodeficiency virus (HIV) prevention and care literature, researchers have explored the association between relational cognitions and HIV-related behaviors that place YGBM at greater risk for HIV. Bauermeister et al. (2011), for example, examined how single, YGBM conceptualized their relational cognitions surrounding their desired passion, intimacy, and commitment in a same-sex relationship using the Sternberg's Triadic Love Scale (Bauermeister et al., 2011). Among these cognitions, commitment was negatively associated with likelihood of engaging in condomless anal sex in a subsequent analysis (Bauermeister, 2012). In a separate study, Bauermeister et al. (2012) also found evidence that romantic obsession, which is related to dependence, insecurity and doubt was positively associated with condomless anal sex among YGBM (Bauermeister et al., 2012). More recently, Cook et al. (2018) found greater romantic fear about not being in a romantic relationship was positively associated with increased receptive condomless anal sex among YGBM, while greater perceived romantic control of relationship functioning was positively associated with both insertive and receptive condomless anal sex (Cook et al., 2018). These findings highlight the potential nuance of relational cognitions on YGBM's sexual decision-making and sexual health.

\section{2 | CURRENT STUDY}

Although most relational cognition measures have been developed to account for heterosexual romantic relationships (Sprecher \& Metts, 1989; Vannier \& O'Sullivan, 2017, 2018) we are unaware of relational cognition measures that have been developed specifically for YGBM. Given unique life and dating experiences, accounting for YGBM specific relationships is warranted to better understand how relationships are conceptualized, formed and maintained. Identifying salient relational cognition themes in the literature and reviewing questionnaire items we dichotomized themes into relational beliefs and relational expectations. We define relational beliefs as generalized ideas, attitudes, and views about how a romantic relationship should be, which are informed by 
observational learning from the social environment. Relational expectations are defined as hopes, desires, or fears about romantic relationships which are consequence of beliefs (what people think is going to happen based on what they do). Although related, expectations focus on linking a belief to behavior in hopes of achieving an outcome.

This proposed study attempts to identify how single YGBM conceptualize relational beliefs and expectations. We used existing literature and a priori conceptualization to test how relational items would group together. We hypothesized that there would be eight factors for how YGBM conceptualize relational expectations (passion, similarities, monogamy, breakups, lifestyle, masculinity, love, emotions) and five factors for how YGBM conceptualize relational beliefs (equality, sex, development, individual preferences, permanence). We then tested these a priori conceptualizations with exploratory factor analysis (EFA).

\section{3 | METHODS}

\section{1 | Design}

The Virtual Love Study was an observational cross-sectional survey that examined YGBM's dating experiences online. Individuals were recruited via advertisements on two popular social networking sites, participant referrals, and flyers posted at local venues commonly frequented by YGBM. Recruitment materials specified the incentive offered, eligibility criteria (broad definition of "dating websites") and the survey website. To be eligible, participants had to be between 18 and 24 years old, identify as a male, be gay, bisexual, same gender loving or another man who has sex with men, and had to have reported being single at time of data collection, using a dating website in the past 3 months; and sexual activity with a male partner that they met online in the past 6 months.

\section{2 | Data collection}

The Virtual Love Study ran from July 2012 until January 2013 and had an analytic sample of $N=1638$ from 44 out of 50 states, and Puerto Rico. Participants were asked for their email to serve as their username, and this allowed participants to save answers as they moved through the survey so that they could exit the survey and come back later if needed. Participants completed eligibility screeners, and if inclusion criteria were met, they were prompted to complete consent forms. Consented participants completed an online questionnaire that assessed sociodemographic characteristics, Internet use, ideal relationship and partner characteristics, sexual behaviors, and psychosocial well-being. Participants received a $\$ 10$ electronic gift card for completing the survey. The University of Pittsburgh Institutional Review Board approved the use of these secondary data analyses with deidentified data.

\section{3 | Measures}

The relational beliefs and expectations items were developed from preliminary research from 34 semistructured in-person interviews about experiences of sexual education, dating, and sexual behaviors that were conducted with YGBM. To be eligible for the qualitative interviews, individuals had to identify as male, be between the ages of 18 and 24; be a resident of Michigan; identify as White/Caucasian, Black/African-American, or Hispanic/Latino; identify as gay, bisexual, same gender loving, or another man who has sex with men (MSM); report having used a dating website in the past 3 months; and report single at time of data collection. Based on the results of these preliminary interviews, 75-items were created, which encompassed YGBM's relational beliefs and expectations and 
these items were included in the Virtual Love Study. More information about the qualitative interviews have been published elsewhere (Johns et al., 2012; Pingel et al., 2013; Sullivan et al., 2018).

\subsection{1 | Relational beliefs}

The relational belief questions consisted of 25 items that asked participants about general beliefs about love and romantic relationships. Some example questions included, "It takes time to fall in love, "It is important that romantic relationships develop from friendships," and "Sexual chemistry is important in a romantic relationship." Participants responded through a four-point Likert scale ranging from "Strongly Disagree" (1) to "Strongly Agree" (4).

\subsection{2 | Relational expectations}

The survey included 50 items that asked participants their expectations about romantic relationships. These questions focused specifically on what participants idealized or expected from their own relationship. Some questions included, "I do not want to be monogamous because it means I would have to commit to one person," "My partner's political views must complement mine," and "I can forgive my partner if he has lied to me." Participants responded through a five-point Likert scale ranging from "Not True" (1) to "Very True" (5).

\subsection{3 | Sociodemographic}

We asked participants to input their age, with those who identified between the ages of 18-24 being eligible for the study. Sexual orientation was asked with the question, "How do you self-identify?" (select all). Responses included: Gay/homosexual, bisexual, straight/heterosexual, same-gender loving, MSM, and other. We combined gay/homosexual, same-gender loving and MSM into one category. Race was assessed through the question, "What is your race?" (select all). Responses included: White/Caucasian, Black/African American, Asian/Pacific Islander, Middle Eastern, Native American, and Other. Ethnicity was assessed through the question, "Are you Hispanic/ Latino?" Response: Yes/No. From these race/ethnicity questions, we created the following variables: non-Hispanic White, non-Hispanic Black, Hispanic/Latino, and all other race/ethnicities. Similarly, education was assessed with the question, "What is the highest level of education you have completed?" Responses included: 8th grade or less, some high school, high school/GE, technical school, associate degree, some college, college, some graduate school. Based on these responses we dichotomized to high school or less and any college education.

\subsection{Analytic procedure}

While reviewing the relational belief and expectation items we kept their dichotomization as we found the relational belief items were more focused on generalized ideas of relationships, whereas the expectation items included a behavioral aspect linking a belief to behavior in hopes of achieving a desired outcome. As a result, analyses for relational expectations and relational beliefs were separate. For the current analysis, we excluded three participants with missing data for sexual identity, 28 participants who identified as straight/heterosexual, and 25 participants who identified as "Other" sexual identity. Based on the scope and focus of the research questions and following the lead of other analyses using this data set, we removed these participants resulting in a final sample of $N=1582$. We applied two methods for factor analysis: random split samples and a priori analysis 
(Armstrong \& Soelberg, 1968). Based on existing knowledge, our study utilized a priori analysis, in which we hypothesized how items would group together and the number of factors expected. Using SPSS, we randomly split the sample into roughly two equally sized sub-samples for independent EFA ( $n=880 ; 55 \%$ of sample). The first subsample was used to refine the factor analysis until conceptual and statistical adequacy was achieved. Our second subsample ( $n=702 ; 45 \%$ of sample) of participants was used to verify that the observed factor structure from our EFA was replicated through confirmatory factor analysis (CFA).

EFA was used in the first half-sample and we applied principal axis factoring (PAF) for extraction. PAF was chosen due to the exploratory nature of our research and openness in our measures of relational beliefs and expectations, and our assumption of latent constructs. Correspondingly, varimax orthogonal rotation was applied with the assumption that the factors from our analysis would be uncorrelated. We removed items with rotated factor loadings $<0.45$ or that cross-loaded above 0.5 (Costello \& Osborne, 2005). Following this, CFA was performed to replicate the results found in the EFA with the second half of our sample, ensuring factors loaded in the same direction, did not cross-load $>0.5$, and were unidimensional. We then used the full sample for a final factor analysis to test factor structures and loadings. Internal reliability was assessed with Cronbach's $a$ for each analysis. Posthoc pearsons correlations and Tukey's Honest Significant Difference (HSD) test were used to compare within group differences using omnibus tests of significance and pairwise tests of significance in scale responses from analysis of variance (ANOVA). Analyses were generated using SPSS (IBM Corp. Released 2017. IBM SPSS Statistics for Windows, Version 25.0; IBM Corp.).

\section{4 | RESULTS}

\section{1 | Sample characteristics}

The total sample for the study was $N=1582$. The average age for participants was 20.77 ( $S D=1.90$; with $96.7 \%$ of the sample identifying as gay, homosexual, same gender loving or MSM, and $3.3 \%$ identifying as bisexual. The majority of our sample identified as non-Hispanic White (65.4\%), followed by Hispanic/Latino ethnicity (17.1\%), all other races/ethnicities (9.0\%), and non-Hispanic Black (8.5\%). The majority of the sample had some college education $(75.0 \%)$, while a quarter had a high school education or less $(25.0 \%)$. To ensure our split samples were equivalent, we tested group differences using $\chi^{2}$ tests and $t$ tests and found no significant differences between groups (results not shown). Full sample demographics are in Table 1.

\subsection{Exploratory factor analysis}

We conceptualized eight factors for the relational expectation and ideation questions. First we assessed the Kaiser-Meyer-Olkin Measure of Sampling Adequacy (KMO), which was 0.742 , signifying the data were acceptable for factor analysis (Cerny \& Kaiser, 1977; KMO value, 2007). We conducted individual factor analyses from the 50-items using PAF and 13 factors emerged from the data with eigenvalues above 1.0. We subsequently applied varimax rotation, tested all remaining items for further factor reduction. Four factors were reduced or dropped during this process. For example, items from the lifestyle factor loaded onto the restriction factor, masculine and gender norms were combined, and some items from the emotions factor were removed based on factor loading. We tested and removed items that had a factor-loading cut-off below 0.45 or that cross-loaded above 0.5 (Costello \& Osborne, 2005). Six items were removed during this process for a final factor solution of eight factors with an eigenvalue above 1.0, which explained $68 \%$ of the variance. Lastly, we tested reliability with Cronbach's $a$ and six factors had an $a$ score above .7, indicating acceptable reliability (Christmann \& Van Aelst, 2006). EFA results are in Table 2. 
TABLE 1 Sociodemographic results of participants $(N=1582)$

\begin{tabular}{|c|c|}
\hline Variables & $M(S D)$ \\
\hline Age & $20.77(1.90)$ \\
\hline Sexual identity & $N(\%)$ \\
\hline Gay/homosexual/same gender loving/MSM & $1530(96.7)$ \\
\hline Bisexual & $52(3.3)$ \\
\hline \multicolumn{2}{|l|}{ Minority status } \\
\hline Non-Hispanic White & $1034(65.4)$ \\
\hline Non-Hispanic Black & $135(8.5)$ \\
\hline Hispanic/Latino-all races & $271(17.1)$ \\
\hline All other races/ethnicities & $142(9.0)$ \\
\hline \multicolumn{2}{|l|}{ Education } \\
\hline High school or less & $396(25.0)$ \\
\hline Any college & $1186(75.0)$ \\
\hline
\end{tabular}

We conceptualized five factors for the relational belief questions. The $\mathrm{KMO}$ was 0.649 , indicating sampling adequacy is mediocre factor analysis (Cerny \& Kaiser, 1977; KMO value, 2007). We identified six factors within the relational belief questions using PAF and varimax rotation. We then removed cross-loading factors above 0.5 , and items that loaded onto factors below 0.45 in a stepwise process (Costello \& Osborne, 2005). Our final factor solution indicated four factors explaining $66 \%$ of the variance. Lastly, we tested reliability with Cronbach's $a$ and two factors had an $a$ score above 0.7, indicating acceptable reliability (Christmann \& Van Aelst, 2006).

\section{3 | Confirmatory factor analysis}

After completing the EFA, we then used the second sub-sample of participants $(n=702)$ to confirm factors. We applied PAF with varimax rotation the CFA sample and found eight factors within relational expectations and four factors within relational beliefs. CFA also confirmed similar factor loadings found in EFA, with the exception of one item "Expecting a romantic relationship to last forever is unrealistic," which cross-loaded; however cross-loading was not above 0.5 (Costello \& Osborne, 2005). The KMO indicated in the CFA for relational expectations were .768, while the KMO for relational beliefs was .619; both indicated acceptability for factor analysis (KMO value, 2007). The table for CFA results are in Table 2.

Following CFA with the second sub-sample $(n=702)$, we then performed CFA with the full sample of participants $(N=1582)$. We assessed reliability through Cronbach's $a$ and removed constructs which had an $a$ below .70 (Christmann \& Van Aelst, 2006). Next, we performed PAF with varimax rotation and confirmed six factors for relational expectations and two factors for relational beliefs. KMO for relational expectations were 0.764 and 0.654 for relational beliefs, indicating acceptable factor analysis sampling adequacy.

\subsection{Final subscales}

For the relational expectation subscales, we calculated mean scores for each scale, which were out of 5 points. A lower score indicated weaker expectations, and higher scores indicated stronger expectations. For example, in the negative breakup subscale, a score of 1 indicates weaker expectations from a negative breakup, and a score of 5 indicates stronger expectations from a negative breakup. Final subscales for relational expectations were 
TABLE 2 Exploratory and confirmatory factor analysis rotated factor loadings

Rotated factor loadings

EFA $(n=880) \quad$ CFA $(n=702)$

Relational expectations: Factor 1 (restrictions)

\begin{tabular}{|c|c|c|}
\hline $\begin{array}{l}\text { I do not want to be monogamous because it means I would have to commit to only } \\
\text { one person }\end{array}$ & 0.707 & 0.734 \\
\hline I would want to be in a relationship where I'm allowed to date other people & 0.699 & 0.711 \\
\hline Committing to a serious relationship right now would keep me from enjoying my life & 0.611 & 0.621 \\
\hline I would date someone who is into party-and-play (PnP) & 0.595 & 0.614 \\
\hline $\begin{array}{l}\text { The thought of making a long term emotional commitment to a romantic partner is } \\
\text { scary }\end{array}$ & 0.526 & 0.532 \\
\hline It is acceptable for my partner to use drugs & 0.513 & 0.499 \\
\hline I would be willing to have an intense but short relationship & 0.469 & 0.499 \\
\hline
\end{tabular}

Relational expectations: Factor 2 (negative breakups)

$\begin{array}{llc}\text { My self-esteem goes down when a partner breaks up with me } & 0.833 & 0.866 \\ \text { I feel powerless when a partner breaks up with me } & 0.831 & 0.801 \\ \text { Breakups tend to affect my day-to-day activities negatively } & 0.806 & 0.794 \\ \text { I tend to blame myself for my breakups } & 0.616 & 0.559 \\ \text { Relational expectations: Factor 3 (masculine and gender norms) } & 0.815 & 0.837 \\ \text { I only want to date men who are masculine } & 0.735 & 0.770 \\ \text { I only want to date men who are "straight- acting" } & 0.730 & 0.675 \\ \text { I would date an effeminate man } & 0.538 & 0.450\end{array}$

Relational expectations: Factor 4 (optimism)

When a relationship ends, I ultimately leave with a better sense of what I desire in a $\quad 0.879 \quad 0.898$ future relationship

When a relationship ends, I ultimately leave with a better sense of what I can offer in $\quad 0.817$ a future relationship

Relational expectations: Factor 5 (cheating)

If I cheated on my partner I would expect him to break up with me

If my partner cheated on me, I would break up with him

0.805

0.809

Relational expectations: Factor 6 (immediacy)

I tend to know that I'm in love with someone within the first month of dating

0.751

0.720

I tend to tell someone that I love him within the first month of dating

0.771

0.742

Relational expectations: Factor 7 (friends and family)

My partner must have a close relationship with my family

0.714

0.739

My partner must have a close relationship with my friends

0.625

0.644

(Continues) 
TABLE 2 (Continued)

Relational expectations: Factor 8 (similarity)

\begin{tabular}{|c|c|c|}
\hline My partners political views must compliment mine & 0.714 & 0.630 \\
\hline My partners religious views must compliment mine & 0.674 & 0.559 \\
\hline \multicolumn{3}{|l|}{ Relational beliefs: Factor 1 (sex) } \\
\hline Sex is important for a lasting romantic relationship & 0.792 & 0.803 \\
\hline Sex brings two people closer & 0.743 & 0.695 \\
\hline Sexual chemistry is important in a romantic relationship & 0.667 & 0.660 \\
\hline \multicolumn{3}{|l|}{ Relational beliefs: Factor 2 (equality) } \\
\hline I admire romantic relationships where partners seem to be equals & 0.792 & 0.748 \\
\hline I most admire relationships where couples are on the same wavelength & 0.708 & 0.703 \\
\hline \multicolumn{3}{|l|}{ Relational beliefs: Factor 3 (modeling) } \\
\hline I have difficulty identifying nonheterosexual couples whose relationships I admire & 0.553 & 0.672 \\
\hline $\begin{array}{l}\text { There are few gay couples whose romantic relationships I can use as a model in my } \\
\text { own life }\end{array}$ & 0.470 & 0.468 \\
\hline $\begin{array}{l}\text { It is hard to develop a romantic relationship with a man if you have sex with him soon } \\
\text { after you start dating }\end{array}$ & 0.443 & 0.464 \\
\hline \multicolumn{3}{|l|}{ Relational beliefs: Factor 4 (happily ever after) } \\
\hline The purpose of a romantic relationship is building a commitment that will last forever & 0.638 & 0.845 \\
\hline Expecting a romantic relationship to last forever is unrealistic ${ }^{a}$ & 0.558 & 0.413 \\
\hline
\end{tabular}

Abbreviations: CFA, confirmatory factor analysis; EFA, exploratory factor analysis.

${ }^{a}$ Items were reverse coded.

restrictions $(M=1.95, S D=0.79)$, negative break ups $(M=2.84, S D=1.06)$, masculine and gender norms $(M=3.08$, $S D=1.04)$, optimism $(M=3.54, S D=1.10)$, cheating $(M=3.79, S D=1.13)$, and immediacy $(M=2.18, S D=1.14)$. We calculated mean scores for each relational belief subscale, which were out of 4 points. Lower scores indicated weaker importance of beliefs, and higher scores indicated stronger importance of beliefs. For example, from sex beliefs subscale, a score of 1 would indicate weaker importance of sex in a relationship, and a score of 4 would indicate greater importance of sex. All subscales had a Cronbach's $a$ above .7, and mean scores were calculated for each item, and each subscale. Final subscales for relational beliefs were sex beliefs $(M=3.20, S D=0.61)$ and equality $(M=3.44, S D=0.55)$. Full results are in Table 3 .

We conducted post-hoc analyses to assess within-group differences based on sociodemographics on the finalized subscales. Pearsons correlation results found age was inversely correlated with negative breakup scores $(r=-.06, p=.016)$ and cheating scores $(r=-.10, p<.001)$, and positively correlated with sex beliefs $(r=.11, p<.001)$ scores only. Our ANOVA results from Tukey HSD test found non-Hispanic Black (mean difference $[\mathrm{m} \Delta]=0.30$, $S E=0.07, p<.001)$ and Hispanic/Latino $(m \Delta=0.24, S E=0.05, p<.001)$ participants reported higher scores for restriction compared to non-Hispanic White participants. Non-Hispanic White $(m \Delta=-0.22, S E=0.07, p=.019)$ and non-Hispanic Black ( $m \Delta=-0.34, S E=0.11, p=.015)$ participants reported lower scores on negative breakup compared to Hispanic/Latino participants. Hispanic/Latino participants reported higher scores on immediacy compared to non-Hispanic White participants $(m \Delta=0.21, S E=0.08, p=.040)$. Non-Hispanic Black participants reported lower 
TABLE 3 Final subscales, mean scores, and reliability

\section{Relational expectations}

Restrictions ( $\alpha: .790)$

I do not want to be monogamous because it means I would have to commit to only one person

I would want to be in a relationship where I'm allowed to date other people

Committing to a serious relationship right now would keep me from enjoying my life

I would date someone who is into party-and-play $(\mathrm{PnP})$

The thought of making a long term emotional commitment to a romantic partner is scary

It is acceptable for my partner to use drugs

I would be willing to have an intense but short relationship

Negative Breakups ( $\alpha$ : .855)

My self-esteem goes down when a partner breaks up with me

I feel powerless when a partner breaks up with me

Breakups tend to affect my day-to-day activities negatively

I tend to blame myself for my breakups

Masculine and gender norms ( $\alpha: .771)$

I only want to date men who are masculine

I only want to date men who are "straight- acting"

I would date an effeminate man $^{a}$

I would date a man who does drag

Optimism ( $\alpha: 0.856)$

When a relationship ends, I ultimately leave with a better sense of what I desire in a future relationship

When a relationship ends, I ultimately leave with a better sense of what I can offer in a future relationship

Cheating ( $\alpha: .769)$

If I cheated on my partner, I would expect him to break up with me

If my partner cheated on me, I would break up with him

Immediacy ( $\alpha: .741)$

I tend to tell someone that I love him with someone within the first month of dating

I tend to know when I'm in love with someone within the first month of dating

\section{Relational beliefs}

Sex beliefs ( $\alpha$ : .773)

Sex is important for a lasting romantic relationship

Sex brings two people closer

Sexual chemistry is important in a romantic relationship

Equality ( $\alpha: .727)$
Total: $3.79(1.13)$

$3.97(1.18)$

$2.48(1.32)$

Total: $2.18(1.14)$

$2.48(1.32)$

$1.92(1.24)$

Total: 3.20 (0.61) $3.13(.805)$

$3.19(.729)$

$3.31(.650)$

$M(S D)$

Total: 1.95 (0.79)

1.64 (1.095)

1.47 (0.982)

1.83 (1.198)

1.79 (1.156)

2.43 (1.288)

2.55 (1.343)

Total: 2.84 (1.06)

3.22 (1.435)

$2.72(1.450)$

2.85 (1.370)

2.75 (1.387)

Total 3.08 (1.04)

$2.80(1.393)$

2.48 (1.358)

3.26 (1.330)

3.87 (1.328)

Total: 3.54 (1.10)

$3.62(1.17)$

$3.50(1.18)$

Total: 3.44 (0.55)
2.10 (1.281)

(Continues) 
TABLE 3 (Continued)

\section{Relational expectations}

I admire romantic relationships where partners seem to be equals

I most admire relationships where couples are on the same wavelength

atems were reverse coded. Table 4.

\section{5 | DISCUSSION}

Our study measured the psychometric proprieties of relational belief and expectation items among single YGBM. We identified six constructs of relational expectations (restrictions, negative break up, masculine and gender norms, optimism, cheating, immediacy) and two constructs of relational beliefs (sex beliefs, equality), with internal validity, and strong reliability.

By focusing on the relational cognitions of single YGBM, we were able to ascertain how YGBM organize their relational beliefs and expectations without the influence of a current relationship and partner (Knobloch \& Theiss, 2010). Among single YGBM, we found high mean scores for relational optimism, which is related to being optimistic of future same-sex relationship $(M=3.54)$. These findings are consistent with findings from prior research, which revealed that most young gay and bisexual participants aspired to have long-term relationships, with more than half wanting monogamous relationships, and more than two-thirds expressing interest in raising children (D'Augelli et al., 2008). The presence of relational optimism in our sample is noteworthy given prior literature suggesting that an individual's ability to envision a positive future in their life (Magaletta \& Oliver, 1999; Snyder et al., 2000) is associated with greater psychological well-being (Bauermeister, 2014). Further research is needed to assess the potentially protective factor of relational optimism on other health outcomes among YGBM (Wienke \& Hill, 2009).

Health promoting cognitions have been related to growth in relationships, communication, expressing love, and problem solving (Sullivan \& Schwebel, 1995). Although prior attempts to organize individuals' relational cognitions have focused on the positive and negative relationship outcomes among heterosexual populations (Holt et al., 2016; Meier \& Allen, 2009; Vannier \& O'Sullivan, 2018), research examining the components that inform these associations has lacked within the sexual and gender minority literature. In our study, we found evidence to indicate that many of the relational features focused on health promoting cognitions. For example, within our construct of optimism, items directly related to personal growth: "When a relationship ends, I ultimately leave with a better sense of what I desire in a future relationship." Further, aspects of communication and expressing love apply to the construct we identified as immediacy: "I tend to tell someone that I love him with someone within the first month of dating." Taken together, these findings suggest that future intervention research should explore the extent to which health promoting cognitions support behavior change and health promotive outcomes.

Our relational expectation factors build on extant literature such as romantic fear, romantic obsession, commitment, intimacy, and passion (Bauermeister et al., 2012; Bauermeister, 2012; Cook et al., 2018). Although some factors were renamed or dropped from our factor analysis, the factors found to be salient in our analysis are largely consistent with our hypothesized factors. Relational restrictions encompass previously identified constructs in the literature such as romantic fear ("The thought of making a long-term emotional commitment to a romantic partner is scary"), commitment ("Committing to a serious relationship right now would keep me from enjoying my life"), and monogamy ("I do not want to be monogamous because it means I would have to commit to only one person"). Expanding on previous literature, relational restrictions explores additional elements more relevant to YGBM such as drug use in romantic relationships ("I would date someone who is into party-and-play (PnP)"). 


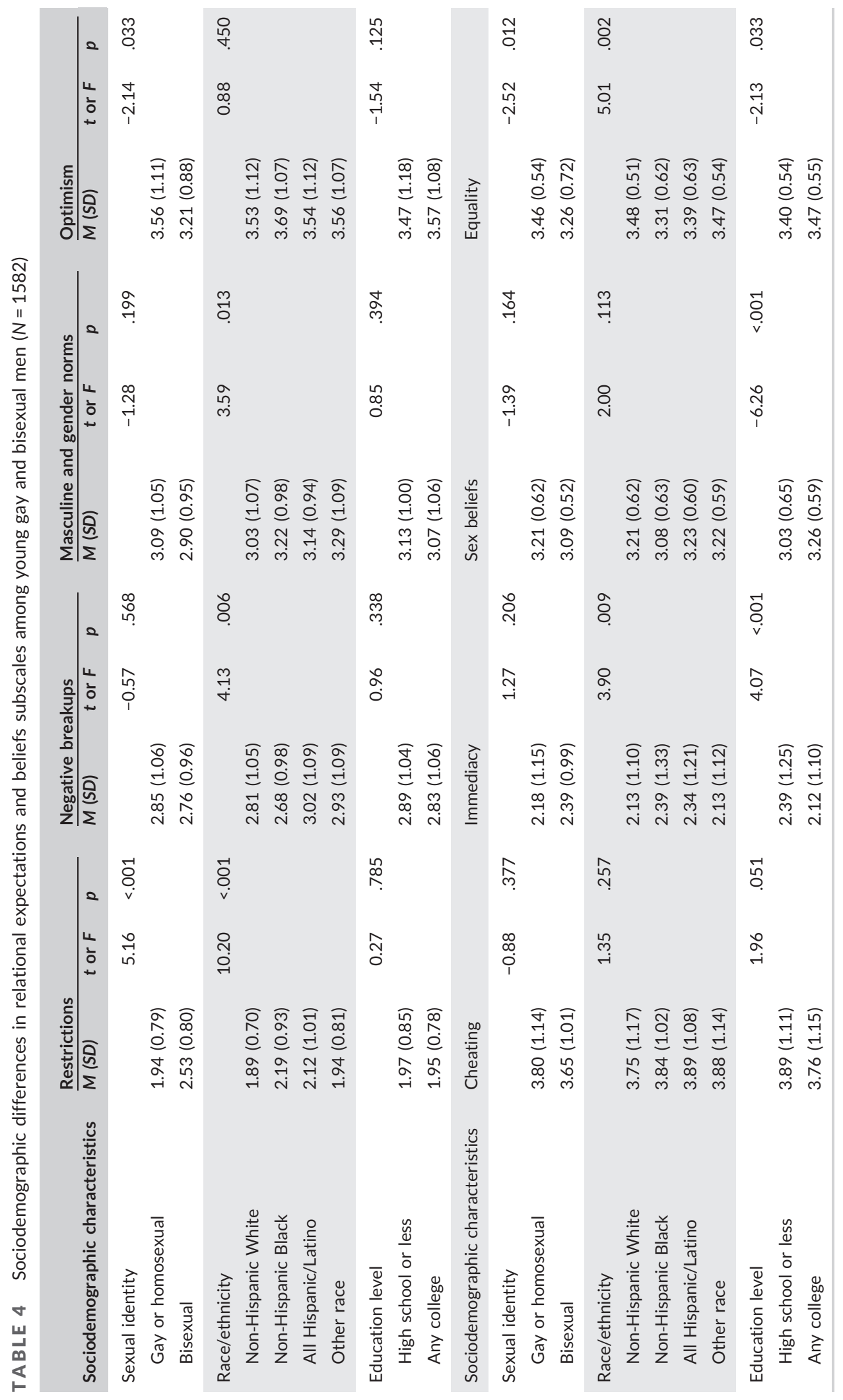


These findings suggest youth's awareness on the prevalence of substance use among GBM communities and their impact on relationships (Caputi et al., 2018). These findings support additional research exploring perceptions about drug use a within the context of YGBM romantic relationships. Given that previous literature identifies substance use as a risk factor for HIV transmission through condomless anal sex (Feinstein et al., 2019; Greenwood et al., 2001), our findings may inform interventions that foster discussions about substance use within romantic relationships (individual and partner use), better equipping YGBM how to address substance use and manage risk in future relationships.

Masculine and gender norms were identified as a significant factor in relational expectations and were unique to our results. Our findings add to existing qualitative and quantitative literature on the significance of gender norms in relationship experiences and meeting new partners for GBM (Johns et al., 2012; Kubicek et al., 2015; Malebranche et al., 2009; Miller \& Behm-Morawitz, 2016). Prior research has indicated GBM's desire to align with hegemonic masculinity norms, with some GBM aspiring to be "straight-acting," and preference for partners who are masculine acting (Carrillo \& Hoffman, 2016; Phua, 2007; Zeglin, 2015). Evidence suggests that masculine and gender norms may especially be crucial for YGBM as these constructs relate to number of sexual partners, attitudes towards condoms, and sexual positioning, and internalized homophobia (Huebner et al., 2002; Johns et al., 2012; Zeglin, 2015). Efforts to address masculine and gender norms and internalized homophobia may also address sexual decision making and safer sex practices.

Our findings indicate that YGBM held strong beliefs regarding cheating. Specifically, if cheating occurred in the relationship, there are expectations that the relationship would end. This construct is closely related to sexual agreements and breaks within sexual agreements. Our study builds upon previous literature, indicating that breaks within sexual agreements widely vary, however, reasons for breaks and consequences for breaks are less known (Rios-Spicer et al., 2019). For YGBM in our study, breaking a sexual agreement may constitute in ending a relationship. However, quantitative findings of GBM in same-sex relationships found younger GBM reported less investment in relationships and were more likely to break nonmonogamous sexual agreements (Perry et al., 2016). Discordance may exist between relational expectations and experiences within relationships, warranting further research. Moreover, our findings on negative break ups indicate YGBM may feel more vulnerable or insecure in romantic relationships and when relationships dissolve. These findings are supported by additional literature indicating negative break up appraisals among YGBM are associated with both higher depressive and anxiety symptoms (Ceglarek et al., 2017). Collectively, LGBTQ+ serving agencies must attend to relationships as a factor in health/well-being. Based on these findings, mental health interventions should incorporate activities that build skills among YGBM to better cope and regulate emotions when experiencing relationship break ups or refer YGBM to appropriate resources such as psychotherapy which can help develop these skills.

Consistent with our original hypothesis, we identified sex beliefs and equality as significant factors for YGBM. Extant literature among heterosexual populations have previously identified sex and equality as significant factors among relational cognitions (Kuo et al., 2017; Luttrell et al., 2018; Sprecher \& Metts, 1989; Vannier \& O'Sullivan, 2017; Young \& Schrodt, 2016), yet these relational beliefs have not been explored among YGBM. Our findings confirm the cohesiveness of these factors in both GBM and heterosexual individuals and suggest the importance of their inclusion in future relationship research with YGBM populations.

This study includes several limitations to consider. First, participants were recruited as a convenience sample with no population frames. Thus, racial/ethnic minority YGBM were not equally represented. Next steps will be to explore these scales among varying ethnic and economic groups. Although our findings are relevant for bisexual men, our study questions only asked about same-sex relationships and did not account for opposite sex relationships. Next steps could explore how relational cognitions may be similar or different among bisexual individuals in opposite sex relationships. Additionally, the cross-sectional data may limit our understanding of relational cognitions, as cognitions may change over time. Furthermore, our study treated relational beliefs and expectations separately as a first step to identify constructs. Future research could apply structural equation modeling to explore how beliefs and expectations inform each other or overlap. Our study also used a split sample 
method for CFA and did not use structural equation modeling to assess the psychometric properties of our subscales. While we are confident in the results of our subscales, we support future research using structural equation modeling to further validate our results. We utilized PAF with varimax rotation to help minimize correlation by trying to maximize the likelihood that an item identifies within a single factor. Next steps include applying these subscales in multivariable models.

\section{6 | IMPLICATIONS}

Our research has broad implications for counseling practice to better support YGBM. First, using the relational belief scale, counselors can gain a better understanding of how YGBM envision romantic relationships. Accordingly, sex within a relationship and equality between partners are important constructs for YGBM. Given the importance of these constructs, counselors can work with clients to discuss power dynamics in relationships and communicating to partners about sex. Further, using the relational expectations scale, counselors can better understand their client's behavioral motivations as they relate to romantic relationship functioning. For example, participants who score highly on relational restrictions may be counselled on how to communicate their wants and needs in a relationship. Additionally, counselors can use the negative break up subscale to gain a better understanding of how their clients handle the emotional burden of a negative break up and develop coping and emotional regulation strategies accordingly. In addition to implications for counselors, subscales may be useful for therapeutic processes to explore and reflect on client's own beliefs and expectations about relationships.

Taken together, both scales measuring relational beliefs and expectations for single YGBM add to growing literature on this topic and have significant practical and clinical implications to improve the health and wellbeing of YGBM.

\section{ACKNOWLEDGEMENTS}

This study was supported by an award from the University of Michigan's Office of the Vice-President for Research (UM-OVPR 5996) and a NIH Career Development Award (K01-MH087242) to Dr. Bauermeister.

\section{CONFLICT OF INTERESTS}

The authors declare that there are no conflict of interests.

\section{PEER REVIEW}

The peer review history for this article is available at https://publons.com/publon/10.1002/jcop.22522.

\section{ORCID}

Jordan M. Sang (D) https://orcid.org/0000-0001-5649-0326

James E. Egan (D) https://orcid.org/0000-0003-3888-7148

Steven P. Meanley (D) https://orcid.org/0000-0002-6098-9733

Mary E. Hawk (D) https://orcid.org/0000-0001-9753-4356

Todd M. Bear (D) https://orcid.org/0000-0001-5252-6926

Derrick D. Matthews (D) https://orcid.org/0000-0002-3579-3608

José A. Bauermeister (D) https://orcid.org/0000-0002-9276-2306

\section{REFERENCES}

Armstrong, J. S., \& Soelberg, P. (1968). On the interpretation of factor analysis. Psychological Bulletin, 70(5), 361-364. 
Bauermeister, J. A. (2012). Romantic ideation, partner-seeking, and hiv risk among young gay and bisexual men. Archives of Sexual Behavior, 41(2), 431-440. https://doi.org/10.1007/s10508-011-9747-z

Bauermeister, J. A. (2014). How statewide LGB policies go from "under our skin" to "into our hearts": Fatherhood aspirations and psychological well-being among emerging adult sexual minority men. Journal of Youth and Adolescence, 43(8), 1295-1305. https://doi.org/10.1007/s10964-013-0059-6

Bauermeister, J. A., Johns, M. M., Pingel, E., Eisenberg, A., Santana, M. L., \& Zimmerman, M. (2011). Measuring love: Sexual minority male youths' ideal romantic characteristics. Journal of LGBT Issues in Counseling, 52(2), 102-121. https://doi. org/10.1080/15538605.2011.574573

Bauermeister, J. A., Johns, M. M., Sandfort, T. G. M., Eisenberg, A., Grossman, A. H., \& D'Augelli, A. R. (2010). Relationship trajectories and psychological well-being among sexual minority youth. Journal of Youth and Adolescence, 39(10), 1148-1163. https://doi.org/10.1007/s10964-010-9557-y

Bauermeister, J. A., Ventuneac, A., Pingel, E., \& Parsons, J. T. (2012). Spectrums of love: Examining the relationship between romantic motivations and sexual risk among young gay and bisexual men. AIDS and Behavior, 16(6), 1549-1559. https://doi.org/10.1007/s10461-011-0123-8

Caputi, T. L., Smith, L. R., Strathdee, S. A., \& Ayers, J. W. (2018). Substance use among lesbian, gay, bisexual, and questioning adolescents in the United States, 2015. American Journal of Public Health, 108(8), 1031-1034. https://doi.org/10. 2105/AJPH.2018.304446

Carrillo, H., \& Hoffman, A. (2016). From MSM to heteroflexibilities: Non-exclusive straight male identities and their implications for HIV prevention and health promotion. Global Public Health, 11(7-8), 923-936. https://doi.org/10. 1080/17441692.2015.1134272

Ceglarek, P. J. D., Darbes, L. A., Stephenson, R., \& Bauermeister, J. A. (2017). Breakup-related appraisals and the psychological well-being of young adult gay and bisexual men. Journal of Gay \& Lesbian Mental Health, 21(3), $256-274$. https://doi.org/10.1080/19359705.2017.1293579

Cerny, C. A., \& Kaiser, H. F. (1977). A study of a measure of sampling adequacy for factor-analytic correlation matrices. Multivariate Behavioral Research, 12(1), 43-47. https://doi.org/10.1207/s15327906mbr1201_3

Christmann, A., \& Van Aelst, S. (2006). Robust estimation of Cronbach's alpha. Journal of Multivariate Analysis, 97(7), 1660-1674. https://doi.org/10.1016/j.jmva.2005.05.012

Collibee, C., \& Furman, W. (2016). The relationship context for sexual activity and its associations with romantic cognitions among emerging adults. Emerging Adulthood, 4(2), 71-81. https://doi.org/10.1177/2167696815604529

Collins, W. A., Welsh, D. P., \& Furman, W. (2009). Adolescent romantic relationships. Annual Review of Psychology, 60(1), 631-652. https://doi.org/10.1146/annurev.psych.60.110707.163459

Cook, S. H., Halkitis, P. N., \& Kapadia, F. (2018). Relationship cognitions and longitudinal trajectories of sexual risk behavior among young gay and bisexual men: The P18 cohort study. Journal of health psychology, 23(14), 1884-1894. https:// doi.org/10.1177/1359105316671187

Costello, A. B., \& Osborne, J. W. (2005). Best practices in exploratory factor analysis: Four recommendations for getting the most from your analysis. Practical Assessment, Research and Evaluation, 10(7), 1-9.

D'Augelli, A. R., Rendina, H. J., Sinclair, K. O., \& Grossman, A. H. (2008). Lesbian and gay youth's aspirationsfor marriage and raising children. Journal of LGBT Issues in Counseling, 1, 77-98.

Feinstein, B. A., Moran, K. O., Newcomb, M. E., \& Mustanski, B. (2019). Differences in HIV risk behaviors between selfidentified gay and bisexual young men who are HIV-negative. Archives of Sexual Behavior, 48(1), 261-275. https://doi. org/10.1007/s10508-018-1148-0

Furman, W., \& Schaffer, L. (2003). The role of romantic relationships in adolescent development. In P. Florsheim (Ed.), Adolescent romantic relations and sexual behavior: Theory, research, and practical implications (pp. 3-22). Lawrence Erlbaum Associates Publishers.

Greenwood, G. L., White, E. W., Page-Shafer, K., Bein, E., Osmond, D. H., Paul, J., \& Stall, R. D. (2001). Correlates of heavy substance use among young gay and bisexual men: The San Francisco Young Men's Health Study. Drug and Alcohol Dependence, 61(2), 105-112. https://doi.org/10.1016/S0376-8716(00)00129-0

Holt, L. J., Mattanah, J. F., Schmidt, C. K., Daks, J. S., Brophy, E. N., Minnaar, P. Y., \& Rorer, K. (2016). Effects of relationship education on emerging adults' relationship beliefs and behaviors: Effects of a relationship intervention. Personal Relationships, 23(4), 723-741. https://doi.org/10.1111/pere.12147

Huebner, D. M., Davis, M. C., Nemeroff, C. J., \& Aiken, L. S. (2002). The impact of internalized homophobia on HIV preventive interventions. American Journal of Community Psychology, 30(3), 327-348. https://doi.org/10.1023/ A:1015325303002

Johns, M. M., Pingel, E., Eisenberg, A., Santana, M. L., \& Bauermeister, J. (2012). Butch tops and femme bottoms? sexual positioning, sexual decision making, and gender roles among young gay men. American Journal of Men's Health, 6(6), 505-518. https://doi.org/10.1177/1557988312455214

Kaiser-Meyer-Olkin value (KMO value). (2007). Dictionary of psychological testing, assessment and treatment. 
Knobloch, L. K., \& Theiss, J. A. (2010). An actor-Partner interdependence model of relational turbulence: Cognitions and emotions. Journal of Social and Personal Relationships, 27(5), 595-619. https://doi.org/10.1177/0265407510368967

Kubicek, K., McNeeley, M., \& Collins, S. (2015). Same-sex relationship in a straight world: Individual and societal influences on power and control in young men's relationships. Journal of Interpersonal Violence, 30(1), 83-109. https://doi.org/10. $1177 / 0886260514532527$

Kuo, S. I. C., Wheeler, L. A., Updegraff, K. A., McHale, S. M., Umaña-Taylor, A. J., \& Perez-Brena, N. J. (2017). Parental modeling and deidentification in romantic relationships among mexican-origin youth: Parental modeling and deidentification. Journal of Marriage and Family, 79(5), 1388-1403. https://doi.org/10.1111/jomf.12411

Luttrell, T. B., Distelberg, B., Wilson, C., Knudson-Martin, C., \& Moline, M. (2018). Exploring the relationship balance assessment. Contemporary Family Therapy, 40(1), 10-27. https://doi.org/10.1007/s10591-017-9421-2

Magaletta, P. R., \& Oliver, J. M. (1999). The hope construct, will, and ways: Their relations with self-efficacy, optimism, and general well-being. Journal of Clinical Psychology, 55(5), 539-551. https://doi.org/10.1002/(SICI)1097-4679(199905) 55:5<539::AID-JCLP2>3.0.CO;2-G

Malebranche, D. J., Fields, E. L., Bryant, L. O., \& Harper, S. R. (2009). Masculine socialization and sexual risk behaviors among black men who have sex with men: A qualitative exploration. Men and masculinities, 12(1), 90-112. https://doi. org/10.1177/1097184X07309504

Meier, A., \& Allen, G. (2009). Romantic relationships from adolescence to young adulthood: Evidence from the National Longitudinal Study of Adolescent Health. The Sociological Quarterly, 50(2), 308-335. https://doi.org/10.1111/j.15338525.2009.01142.x

Meyer, I. H. (2003). Prejudice, social stress, and mental health in lesbian, gay, and bisexual populations: Conceptual issues and research evidence. Psychological Bulletin, 129(5), 674-697. https://doi.org/10.1037/0033-2909.129.5.674

Miller, B., \& Behm-Morawitz, E. (2016). "Masculine Guys Only": The effects of femmephobic mobile dating application profiles on partner selection for men who have sex with men. Computers in Human Behavior, 62, 176-185. https://doi. org/10.1016/j.chb.2016.03.088

Nosko, A., Tieu, T.-T., Lawford, H., \& Pratt, M. W. (2011). How do I love thee? Let me count the ways: Parenting during adolescence, attachment styles, and romantic narratives in emerging adulthood. Developmental Psychology, 47(3), 645-657. https://doi.org/10.1037/a0021814

Perry, N. S., Huebner, D. M., Baucom, B. R., \& Hoff, C. C. (2016). Relationship power, sociodemographics, and their relative influence on sexual agreements among gay male couples. AIDS and Behavior, 20(6), 1302-1314. https://doi.org/10. 1007/s10461-015-1196-6

Phua, V. C. (2007). Contesting and maintaining hegemonic masculinities: Gay Asian American men in mate selection. Sex Roles, 57(11), 909-918. https://doi.org/10.1007/s11199-007-9318-x

Pingel, E. S., Bauermeister, J. A., Johns, M. M., Eisenberg, A., \& Leslie-Santana, M. (2013). A safe way to explore: Reframing risk on the internet amidst young gay men's search for identity. Journal of Adolescent Research, 28(4), 453-478. https://doi.org/10.1177/0743558412470985

Rios-Spicer, R., Darbes, L., Hoff, C., Sullivan, P. S., \& Stephenson, R. (2019). Sexual agreements: A scoping review of measurement, prevalence and links to health outcomes. AIDS and Behavior, 23(1), 259-271. https://doi.org/10.1007/ s10461-018-2212-4

Snyder, C. R., Feldman, D. B., Taylor, J. D., Schroeder, L. L., \& Adams, V. H. (2000). The roles of hopeful thinking in preventing problems and enhancing strengths. Applied and Preventive Psychology, 9(4), 249-269. https://doi.org/10. 1016/S0962-1849(00)80003-7

Soller, B. (2014). Caught in a bad romance: Adolescent romantic relationships and mental health. Journal of Health and Social Behavior, 55(1), 56-72. https://doi.org/10.1177/0022146513520432

Sprecher, S., \& Metts, S. (1989). Development of the 'romantic beliefs scale' and examination of the effects of gender and gender-role orientation. Journal of Social and Personal Relationships, 6(4), 387-411. https://doi.org/10.1177/ 0265407589064001

Stackert, R. A., \& Bursik, K. (2003). Why am I unsatisfied? Adult attachment style, gendered irrational relationship beliefs, and young adult romantic relationship satisfaction. Personality and Individual Differences, 34(8), 1419-1429. https:// doi.org/10.1016/S0191-8869(02)00124-1

Steinberg, L., \& Morris, A. S. (2001). Adolescent development. Annual Review of Psychology, 52(1), 83-110. https://doi.org/ 10.1146/annurev.psych.52.1.83

Sullivan, \& Schwebel (1995). Relationship beliefs and expectations of satisfaction in marital relationships: Implications for family practitioners. The Family Journal, 3(4), 298-305. https://doi.org/10.1177/1066480795034003

Sullivan, S. P., Pingel, E. S., Stephenson, R., \& Bauermeister, J. A. (2018). "It was supposed to be a onetime thing": Experiences of romantic and sexual relationship typologies among young gay, bisexual, and other men who have sex with men. Archives of Sexual Behavior, 47(4), 1221-1230. https://doi.org/10.1007/s10508-017-1058-6 
Vannier, S. A., \& O'Sullivan, L. F. (2017). Passion, connection, and destiny: How romantic expectations help predict satisfaction and commitment in young adults' dating relationships. Journal of Social and Personal Relationships, 34(2), 235-257. https://doi.org/10.1177/0265407516631156

Vannier, S. A., \& O'Sullivan, L. F. (2018). Great expectations: Examining unmet romantic expectations and dating relationship outcomes using an investment model framework. Journal of Social and Personal Relationships, 35(8), 1045-1066. https://doi.org/10.1177/0265407517703492

Wienke, C., \& Hill, G. J. (2009). Does the "marriage benefit" extend to partners in gay and lesbian relationships?: Evidence from a random sample of sexually active adults. Journal of Family Issues, 30(2), 259-289.

Young, J., \& Schrodt, P. (2016). Family communication patterns, parental modeling, and confirmation in romantic relationships. Communication Quarterly, 64(4), 454-475. https://doi.org/10.1080/01463373.2015.1103297

Zeglin, R. J. (2015). Assessing the role of masculinity in the transmission of HIV: A systematic review to inform HIV risk reduction counseling interventions for men who have sex with men. Archives of Sexual Behavior, 44(7), 1979-1990. https://doi.org/10.1007/s10508-015-0501-9

How to cite this article: Sang, J. M., Egan, J. E., Meanley, S. P., Hawk, M. E., Markovic, N., Bear, T. M., Matthews, D. D., Bauermeister, J. A. (2021). Expectations and beliefs: How single young gay, bisexual and other men who have sex with men envision romantic relationships. Journal of Community Psychology, 1-16.

https://doi.org/10.1002/jcop.22522 